\title{
Over-expression of TLR3 in human endometrial cancer.
}

Shahan Mamoor, $\mathrm{MS}^{1}$

${ }^{1}$ shahanmamoor@gmail.com

4 East Islip, NY USA

Gynecologic cancers including cancers of the endometrium are a clinical problem ${ }^{1-4}$. We mined published microarray data ${ }^{5,6}$ to discover genes associated with endometrial cancers by comparing transcriptomes of the normal endometrium and endometrial tumors from humans. We identified the double-stranded ribonucleic acid (RNA) sensor TLR $3^{7-9}$ as among the most differentially expressed genes, transcriptome-wide, in cancers of the endometrium. TLR3 was expressed at significantly higher levels in endometrial tumor tissues as compared to the endometrium. However, higher primary tumor expression of TLR3 was correlated with significantly improved overall survival in patients with endometrial cancer. Together, the data reveal over-expression of TLR3 in human endometrial cancer and indicate activation of a viral nucleic acid sensor in cancers of the endometrium.

Keywords: endometrial cancer, gynecologic cancers, endometrium, TLR3. 
Endometrial cancer is the most common gynecologic cancer in the developed world ${ }^{1}$. Over the last three decades, the incidence of endometrial cancer has increased $21 \%{ }^{4}$ and the death rate has increased $100 \%{ }^{3}$. We harnessed the power of independently published microarray datasets ${ }^{5,6}$ to determine in an unbiased fashion and at the systems-level genes most differentially expressed in endometrial tumors. We report here the differential and increased expression of the viral dsRNA sensor toll-like receptor 3 (TLR3).

\section{$\underline{\text { Methods }}$}

We utilized datasets GSE63678 5 and GSE17025 $5^{6}$ for this global differential gene expression analysis of human endometrial cancer in conjunction with GEO2R. GSE63678 was generated using Affymetrix Human Genome U133A 2.0 Array technology with $n=5$ control endometrial tissues (including $n=4$ uterine myomas and $n=1$ benign cyst) and $n=7$ endometrial cancers (including $n=2$ endometrial adenocarcinomas, $n=3$ mixed endometrioid adenocarcinomas, and $n=2$ adenocarcinomas with squamous differentiation); analysis was performed using platform GPL571. GSE17025 was generated using Affymetrix Human Genome U133 Plus 2.0 Array technology with $n=5$ normal endometrial tissues (inactive endometrium) and $n=91$ endometrial cancers; analysis was performed using platform GPL570. The Benjamini and Hochberg method of $p$-value adjustment was used for ranking of differential expression but raw $p$-values were used to assess statistical significance of global differential expression.

Log-transformation of data was auto-detected, and the NCBI generated category of platform annotation was used. A statistical test was performed to evaluate whether TLR3 gene expression was significantly different between primary tumors of the breast and brain metastases in humans with breast cancer using a two-tailed t-test. For Kaplan-Meier survival analysis, we used the Kaplan-Meier plotter tool ${ }^{10}$ for correlation of TLR3 mRNA expression levels with overall survival in $n=543$ endometrial cancer patients.

\section{$\underline{\text { Results }}$}

We harnessed the power of blind comparative transcriptome analysis using published microarray data ${ }^{5,6}$ to discover in an unbiased fashion genes associated with endometrial cancer in humans.

\section{TLR3 is differentially expressed in endometrial cancer.}

We identified the toll-like receptor TLR3 as among the genes most differentially expressed in cancers of the endometrium when compared to benign endometrial tissues (Chart 1). When sorting each of the genes expressed in endometrial tumor tissue based on significance of change in expression as compared to benign endometrial tissue, TLR3 ranked 111 out of 22273 transcripts, equating to $99.5 \%$ differential expression (Chart 1). Differential expression of TLR3 in human endometrial cancers was statistically significant (Chart $1 ; p=1.10 \mathrm{E}-04)$. 
We queried a second microarray data to validate differential expression of TLR3 in endometrial cancer. Again, we observed differential expression of TLR3 when comparing endometrial tumor tissue to benign endometrial tissue (Chart 2). When sorting each of the genes expressed in endometrial tumor tissue based on significance of change in expression as compared to benign endometrial tissue, TLR3 ranked 11521 out of 54675 transcripts, equating to $78.9 \%$ differential expression (Chart 2). Differential expression of TLR3 in human endometrial cancers trended towards statistical significance (Chart 2; $p=6.03 \mathrm{E}-02$ ).

\section{TLR3 is expressed at significantly higher levels in endometrial cancers as compared to benign endometrial tissue.}

We obtained exact mRNA expression levels for TLR3 in endometrial tumor tissues and from benign endometrial tissue to evaluate direction and statistical significance of change in expression of TLR3 in human endometrial cancer. TLR3 was expressed at higher levels in endometrial tissue as compared to normal endometrial tissue, and this difference was statistically significant (Figure $1 ; p=0.000262$ ).

\section{TLR3 expression is correlated with patient survival outcomes in endometrial cancer.}

We performed Kaplan-Meier survival analysis to evaluate correlation between TLR3 primary tumor expression and survival outcomes in 543 patients with endometrial cancer. We observed a significant correlation between primary tumor expression of TLR3 and overall survival in patients with endometrial cancer (Figure 2). Patients whose primary tumors expressed low levels of TLR3 possessed median OS of 43.9 months, while patients whose tumors expressed high levels of TLR3 possessed median OS of 108.37 months. This difference in OS based on TLR tumor expression in patients with endometrial cancer was statistically significant (Figure 2, Chart 3; logrank $p$-value: 0.018; hazard ratio: $0.6(0.39-0.92))$.

Thus, by mining published microarray data ${ }^{5,6}$ in an unbiased and systematic fashion, we identified toll-like receptor 3, encoded by TLR3, as among the genes whose expression was most different, transcriptome-wide, in the endometrial tumor tissue of patients with endometrial cancer when compared to benign endometrial tissue; we observed significantly increased expression of TLR3 in endometrial tumor tissue as compared to benign endometrial tissue. Further, we found a significant correlation between TLR3 expression and patient survival outcomes in human endometrial cancer, as overall survival was significantly greater in patients whose tumors expressed higher levels of TLR3 as compared to patients whose tumors expressed lower levels of TLR3. 


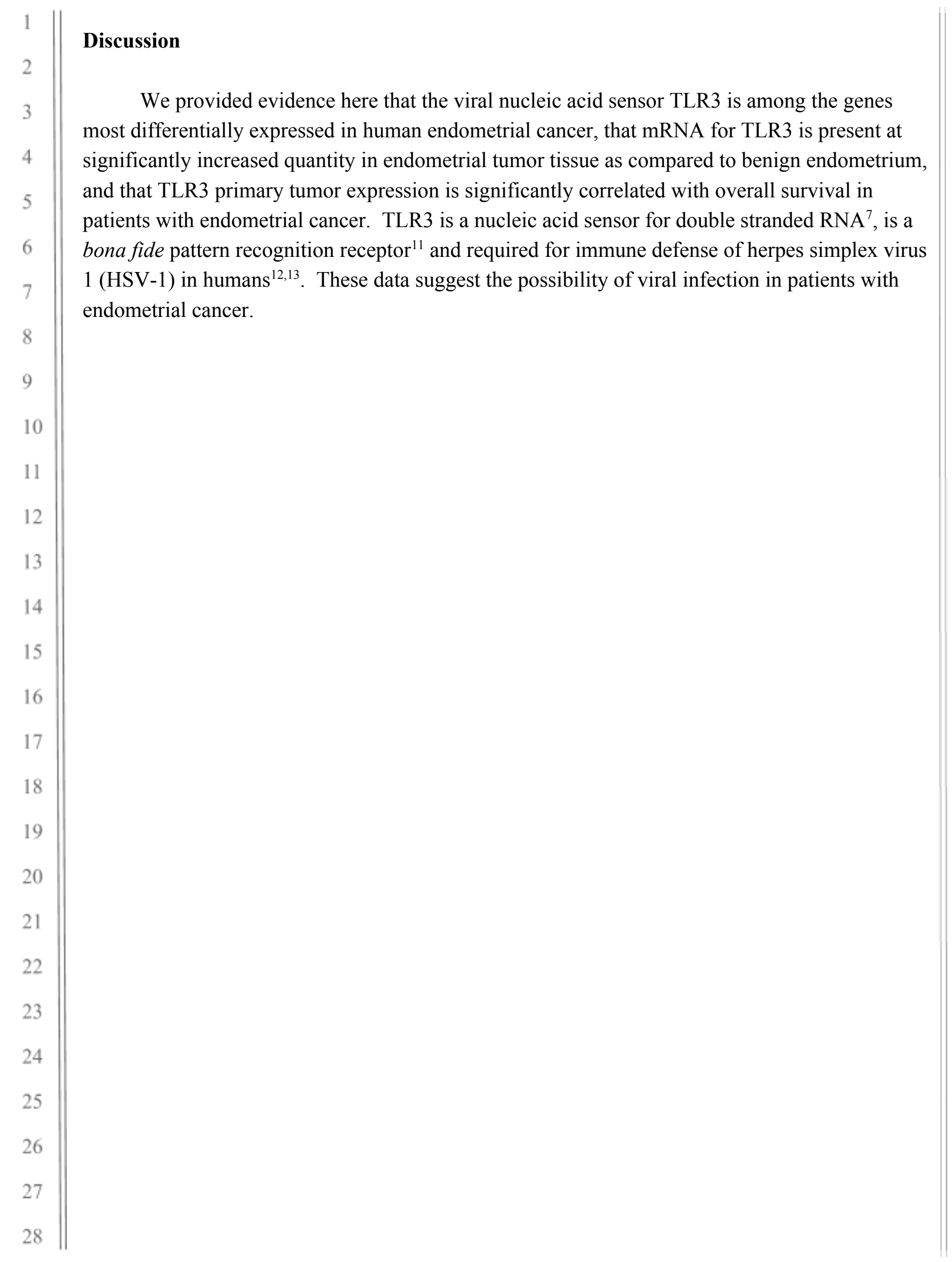




\section{References}

1. Amant, F., Moerman, P., Neven, P., Timmerman, D., Van Limbergen, E. and Vergote, I., 2005. Endometrial cancer. The Lancet, 366(9484), pp.491-505.

2. Sorosky, J.I., 2008. Endometrial cancer. Obstetrics \& Gynecology, 111(2), pp.436-447.

3. Morice, P., Leary, A., Creutzberg, C., Abu-Rustum, N. and Darai, E., 2016. Endometrial cancer. The Lancet, 387(10023), pp.1094-1108.

4. Sorosky, J.I., 2012. Endometrial cancer. Obstetrics \& Gynecology, 120(2 Part 1), pp.383-397.

5. Pappa, K.I., Polyzos, A., Jacob-Hirsch, J., Amariglio, N., Vlachos, G.D., Loutradis, D. and Anagnou, N.P., 2015. Profiling of discrete gynecological cancers reveals novel transcriptional modules and common features shared by other cancer types and embryonic stem cells. PLoS One, 10(11), p.e0142229.

6. Day, R.S., McDade, K.K., Chandran, U.R., Lisovich, A., Conrads, T.P., Hood, B.L., Kolli, V.K., Kirchner, D., Litzi, T. and Maxwell, G.L., 2011. Identifier mapping performance for integrating transcriptomics and proteomics experimental results. BMC bioinformatics, 12(1), p.213.

7. Alexopoulou, L., Holt, A.C., Medzhitov, R. and Flavell, R.A., 2001. Recognition of double-stranded RNA and activation of NF- $\kappa$ B by Toll-like receptor 3. Nature, 413(6857), pp.732-738.

8. Salaun, B., Coste, I., Rissoan, M.C., Lebecque, S.J. and Renno, T., 2006. TLR3 can directly trigger apoptosis in human cancer cells. The Journal of Immunology, 176(8), pp.4894-4901.

9. Matsumoto, M., Oshiumi, H. and Seya, T., 2011. Antiviral responses induced by the TLR3 pathway. Reviews in medical virology, 21(2), pp.67-77.

10. Nagy, A., Munkacsy, G. and Gyorffy, B., 2020. Pancancer survival analysis of cancer hallmark genes. bioRxiv.

11. Liu, L., Botos, I., Wang, Y., Leonard, J.N., Shiloach, J., Segal, D.M. and Davies, D.R., 2008. Structural basis of toll-like receptor 3 signaling with double-stranded RNA. Science, 320(5874), pp.379-381.

12. Zhang, S.Y., Jouanguy, E., Ugolini, S., Smahi, A., Elain, G., Romero, P., Segal, D., Sancho-Shimizu, V., Lorenzo, L., Puel, A. and Picard, C., 2007. TLR3 deficiency in patients with herpes simplex encephalitis. Science, 317(5844), pp.1522-1527.

13. Guo, Y., Audry, M., Ciancanelli, M., Alsina, L., Azevedo, J., Herman, M., Anguiano, E., Sancho-Shimizu, V., Lorenzo, L., Pauwels, E. and Philippe, P.B., 2011. Herpes simplex virus encephalitis in a patient with complete TLR3 deficiency: TLR3 is otherwise redundant in protective immunity. Journal of Experimental Medicine, 208(10), pp.2083-2098. 


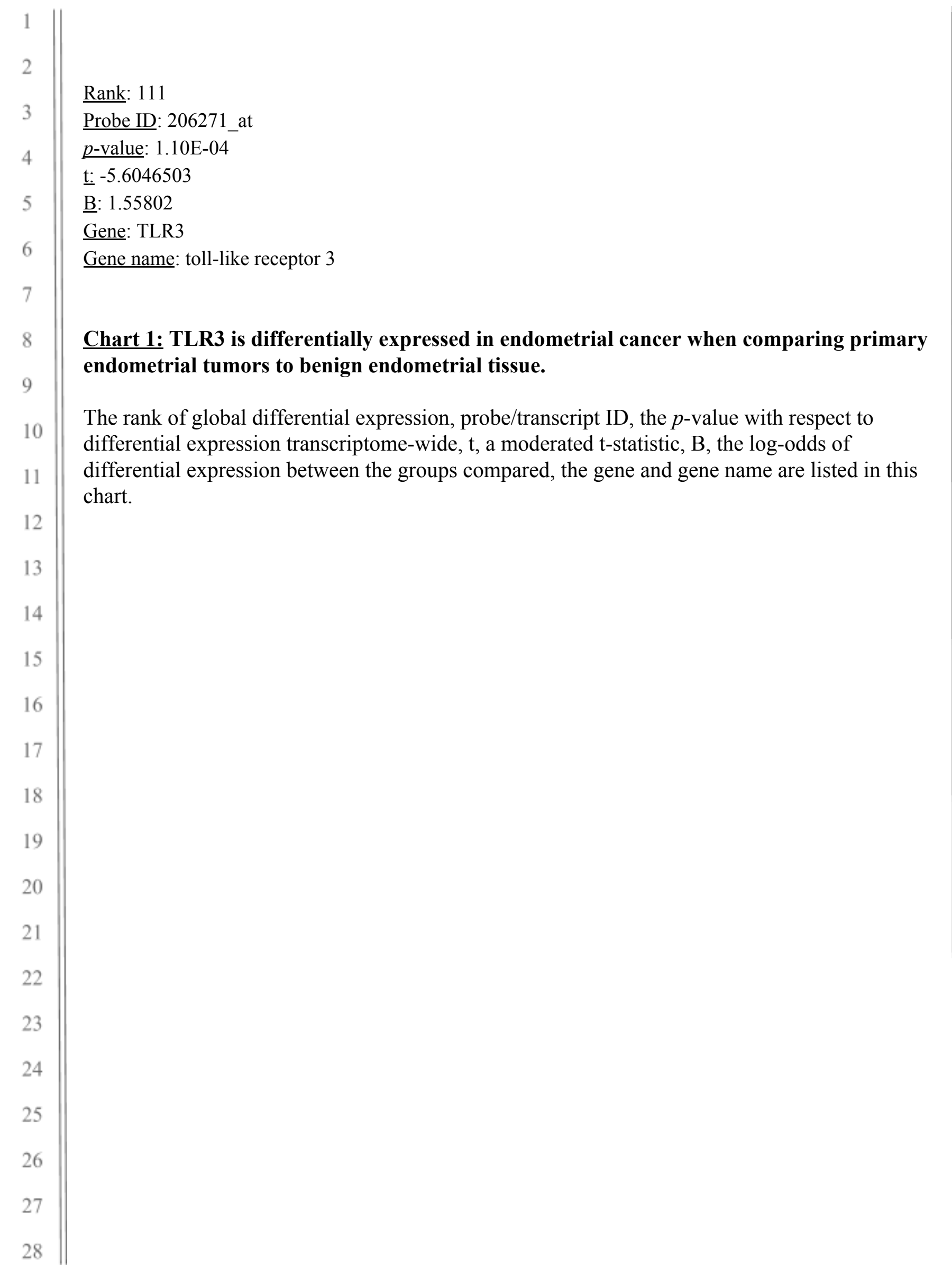




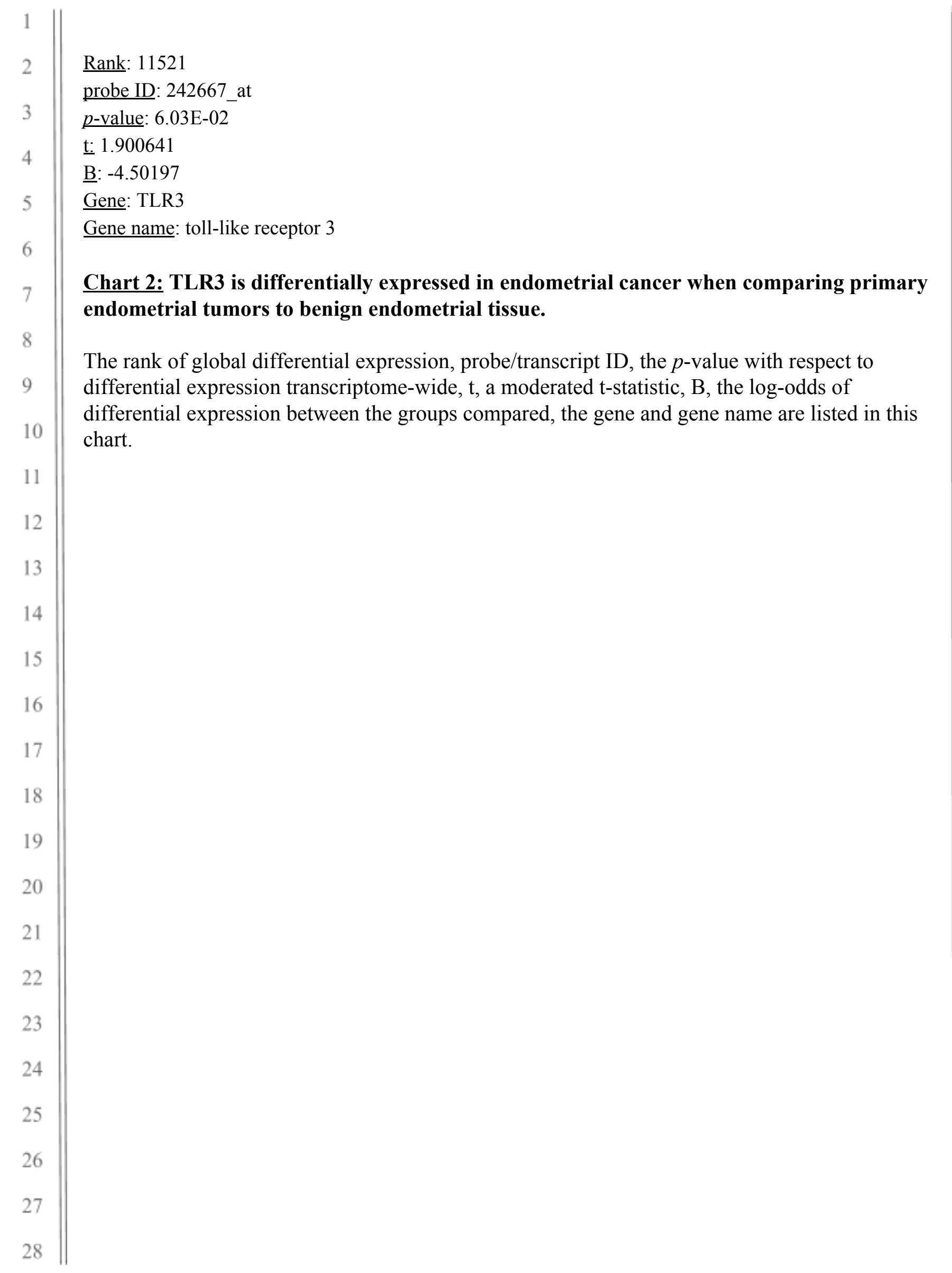


8

\section{7}

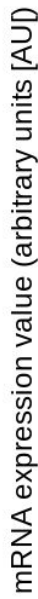

6

5

5

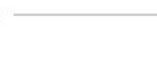

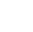

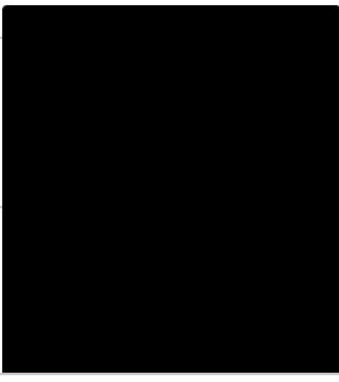

Benign Endometrium

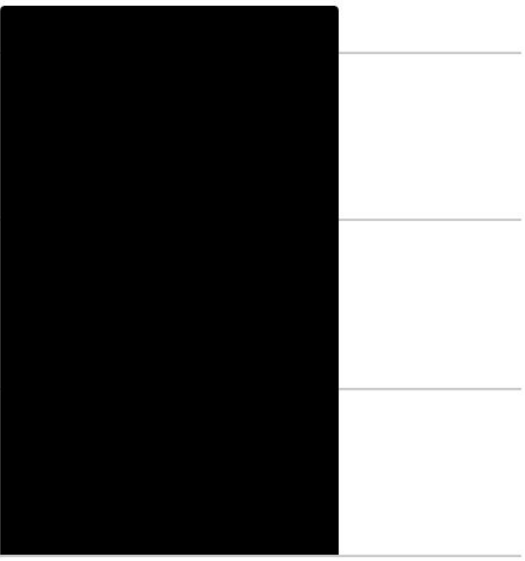

Endometrial Cancer

Figure 1: TLR3 is expressed at significantly higher levels in the endometrial tumors of patients with endometrial cancer when compared to benign endometrium.

The mRNA expression level of TLR3 in benign endometrial tissue (left) and in primary tumors of the endometrium (right) is graphically depicted; the result of a statistical test evaluating significance of difference in TLR3 expression between benign endometrial tissue and primary tumors of the endometrial tissue is $p=0.000262$. 


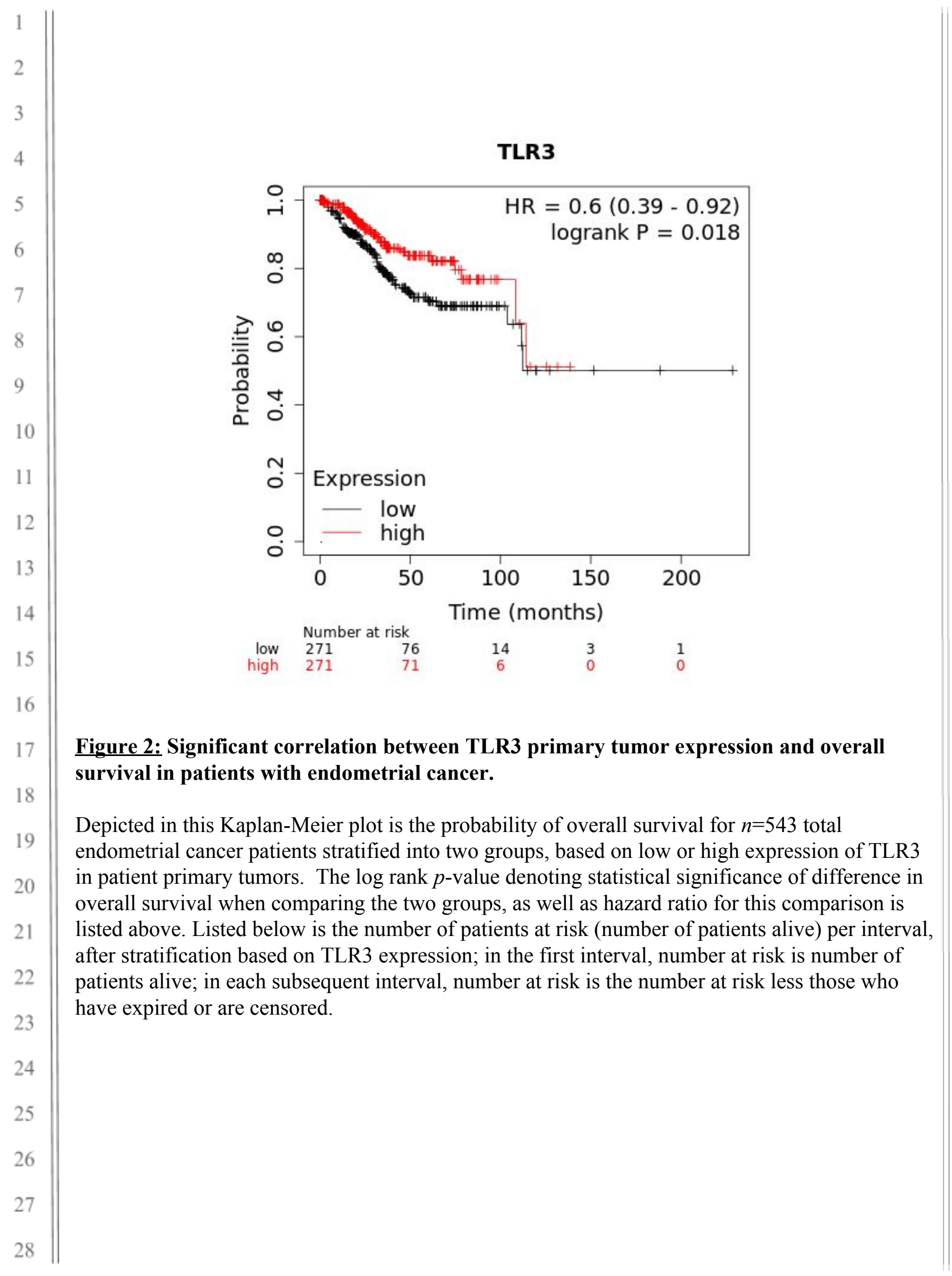




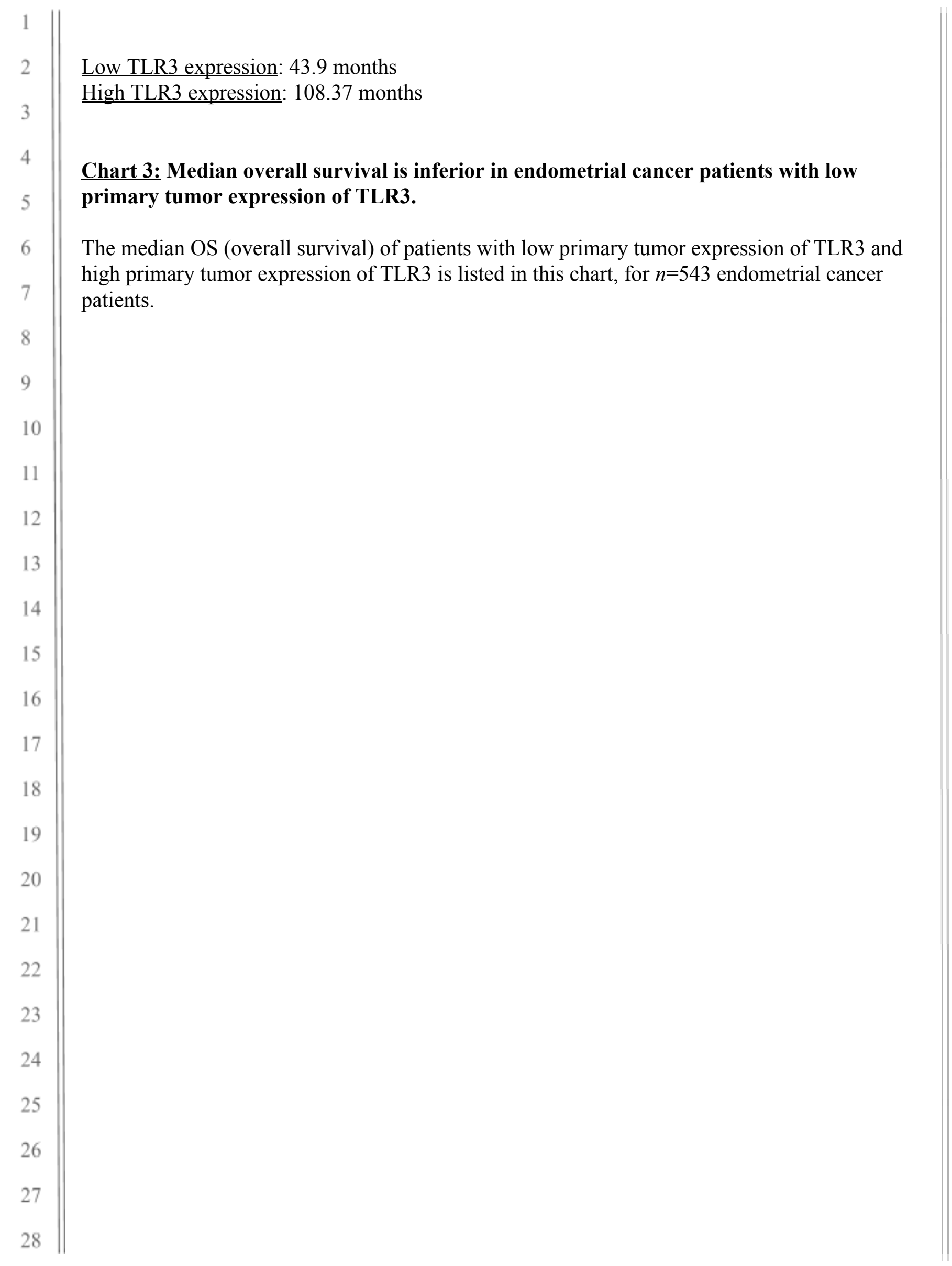

